\title{
Miniaturized Amperometric Solid Electrolyte Carbon Dioxide Sensors
}

\author{
G. W. Hunter, ${ }^{a *}$ J. C. Xu, ${ }^{\mathrm{a}}$ C. C. Liu, ${ }^{\mathrm{b}}$ J. W. Hammond, ${ }^{\mathrm{b}}$ B. Ward, ${ }^{\mathrm{c}}$ D. Lukco, ${ }^{\mathrm{d}}$ \\ P. Lampard, ${ }^{\mathrm{e}}$ M. Artale, ${ }^{\mathrm{e}}$ and D. Androjna ${ }^{\mathrm{e}}$ \\ ${ }^{a}$ NASA Glenn Research Center, Cleveland, OH 44135, USA \\ ${ }^{\mathrm{b}}$ Electronics Design Center, Case Western Reserve University, Cleveland, OH 44106, USA \\ ${ }^{\mathrm{c}}$ Makel Engineering, Chico, CA 95973, USA \\ ${ }^{\mathrm{d}}$ QSS Group, Inc./ NASA Glenn Research Center, Cleveland, OH 44135, USA \\ ${ }^{\text {e}}$ Sierra Lobo Inc./ NASA Glenn Research Center, Cleveland, OH 44135, USA
}

\begin{abstract}
A miniaturized electrochemical carbon dioxide $\left(\mathrm{CO}_{2}\right)$ sensor using $\mathrm{Na}_{3} \mathrm{Zr}_{2} \mathrm{Si}_{2} \mathrm{PO}_{12}$ (NASICON) as a solid electrolyte has been fabricated and demonstrated. Microfabrication techniques were used for sensor fabrication to yield a sensing area around $1.0 \mathrm{~mm} \times 1.1 \mathrm{~mm}$. The NASICON solid electrolyte and the $\mathrm{Na}_{2} \mathrm{CO}_{3} / \mathrm{BaCO}_{3}$ (1:1.7 molar ratio) auxiliary electrolyte were deposited by sputtering in between and on top of the interdigitated finger-shaped platinum electrodes. This structure maximizes the length of the three-phase boundary (electrode, solid electrolyte, and auxiliary electrolyte), which is critical for gas sensing. The robust $\mathrm{CO}_{2}$ sensor operated up to $600^{\circ} \mathrm{C}$ in an amperometric mode and attempts were made to optimize sensor operating parameters. Concentrations of $\mathrm{CO}_{2}$ between $0.02 \%$ and $4 \%$ were detected and the overall sensor performance was evaluated. Linear response of sensor current output to $\ln \left[\mathrm{CO}_{2}\right.$ concentration] ranging from $0.02 \%$ to $1 \%$ was achieved.
\end{abstract}

\section{Introduction}

The detection of $\mathrm{CO}_{2}$ is essential for a range of applications including reduction of false fire alarms, environmental monitoring, and engine emission monitoring [1]. For example, traditional smoke detectors monitoring particles can have false fire alarm rates as high as 200:1. Alternatively, monitoring the change of $\mathrm{CO}$ and $\mathrm{CO}_{2}$ concentrations and their ratio $\left(\mathrm{CO} / \mathrm{CO}_{2}\right)$ could be used to detect the chemical signature of a fire. Such $\mathrm{CO}$ and $\mathrm{CO}_{2}$ sensors, combined with a traditional smoke detector, are meant to greatly reduce false alarms [2]. Electrochemical $\mathrm{CO}_{2}$ sensors which use super ion conductors (such as NASICON) as solid electrolyte and auxiliary electrolytes (such as $\mathrm{Na}_{2} \mathrm{CO}_{3} / \mathrm{BaCO}_{3}$ ) [3] have great potential for in situ fire detection and other applications. Most bulk material or thick film based electrochemical sensors [4-8] consume high power, and the fabrication processes of these sensors are complicated because of the involvement of hot press and screen printing [6]. In recent years, there has been a significant effort to develop miniaturized electrochemical $\mathrm{CO}_{2}$ sensors. However, they are often still at a comparatively early stage of development [8-10]. Compared to bulk material and thick film solid electrolyte $\mathrm{CO}_{2}$ sensors, miniaturized sensors fabricated by microfabrication techniques generally have the advantages of small size, light weight, low power consumption, and batch fabrication.

This paper describes the development of a miniaturized $\mathrm{CO}_{2}$ sensor based on a NASICON solid electrolyte and $\mathrm{Na}_{2} \mathrm{CO}_{3} / \mathrm{BaCO}_{3}$ (1:1.7 molar ratio) auxiliary electrolytes 
deposited on an interdigitated finger electrode structure. Sensor fabrication, testing, and the detection mechanism are discussed. It is concluded that the interdigitated electrode structure for an electrochemical cell sensor has advantages over two parallel-electrode configurations.

One long-term objective of this work is to fabricate miniaturized $\mathrm{CO}_{2}$ sensors which can be integrated into a sensor array with other sensors as well as electronics, power, and telemetry onto a postage-stamp sized package [1]. The complete system ("Lick and Stick" technology) can be placed at a number of locations like a postage stamp, to give a full-field view of what is occurring in an environment, or integrated into a high temperature gas sensor array for measurement of engine emissions.

\section{Sensing Approach}

A miniaturized amperometric electrochemical carbon dioxide sensor with a novel process of distinctively depositing electrolyte NASICON and auxiliary electrolytes $\mathrm{Na}_{2} \mathrm{CO}_{3} / \mathrm{BaCO}_{3}$ on interdigitated finger electrodes is discussed in this section. $\mathrm{Na}_{2} \mathrm{CO}_{3}$ is the real auxiliary electrolyte whereas $\mathrm{BaCO}_{3}$ is used to reduce possible effects of humidity [3]. This was the first time to our knowledge that two material systems were deposited on the interdigitated finger electrodes distinctively with both electrolyte systems (NASICON and $\mathrm{Na}_{2} \mathrm{CO}_{3} / \mathrm{BaCO}_{3}$ ) contacting the electrodes. This approach forms significantly more three-contact boundaries, i.e., electrode/electrolyte/atmosphere interfaces, compared to other designs with similar dimensions. Since it is these three-contact boundaries that enable the gas sensing, this approach should result in improved sensor sensitivity.

The general sensing mechanism is as follows [3]:

$$
\begin{aligned}
& 2 \mathrm{Na}^{+}+\mathrm{CO}_{2}+1 / 2 \mathrm{O}_{2}+2 \mathrm{e} \rightarrow \mathrm{Na}_{2} \mathrm{CO}_{3} \text { (Working Electrode) } \\
& \mathrm{Na}_{2} \mathrm{O} \rightarrow 2 \mathrm{Na}^{+}+1 / 2 \mathrm{O}_{2}+2 \mathrm{e} \text { (Reference Electrode) } \\
& \mathrm{Na}_{2} \mathrm{O}+\mathrm{CO}_{2} \rightarrow \mathrm{Na}_{2} \mathrm{CO}_{3} \text { (Overall Reaction) }
\end{aligned}
$$

This sensing mechanism implies that the sensor operating temperature is high enough to allow the flow of $\mathrm{Na}$ through the electrolyte. The same sensor structure could also be applied to develop $\mathrm{NO}_{\mathrm{x}}$ sensors with the corresponding auxiliary electrolytes $\mathrm{NaNO}_{2}$ or $\mathrm{NaNO}_{3}$ [11]. The sensing mechanism of the miniature sensor will be discussed in detail later in this paper.

\section{Fabrication}

The fabrication process for miniature carbon dioxide sensors involves three major deposition steps:

1) Deposition of platinum interdigitated finger electrodes on alumina substrates,

2) Deposition of solid electrolyte NASICON $\left(\mathrm{Na}_{3} \mathrm{Zr}_{2} \mathrm{Si}_{2} \mathrm{PO}_{12}\right)$ in between the fingers, and

3) Deposition of auxiliary electrolytes $\mathrm{Na}_{2} \mathrm{CO}_{3} / \mathrm{BaCO}_{3}$ (1:1.7 molar ratio) on top of the entire sensing area.

The basic sensor structure is shown in Fig. 1 and the details of the fabrication procedure are described below. The front side of the sensor includes the interdigitated fingers on 
which the electrolytes are deposited. The back side design of the sensors includes a temperature detector and heater for temperature control and stabilization. The heating and temperature detector elements were not fabricated on the back of the sensor for this sensor evaluation study, but will be applied in future work.

(a)

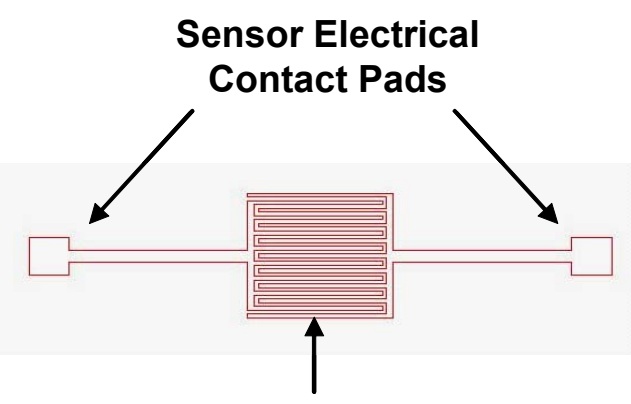

Interdigitated Fingers

Front

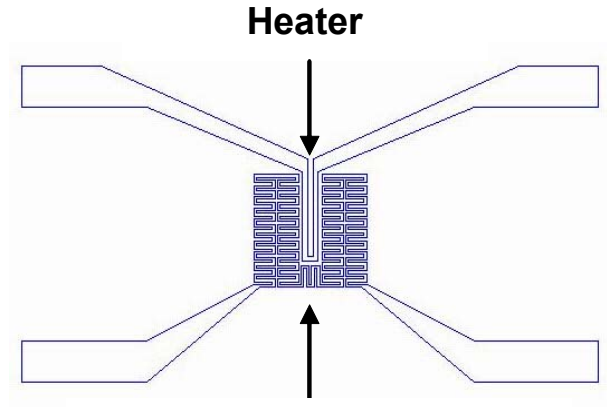

Temperature Detector

Back

(b)

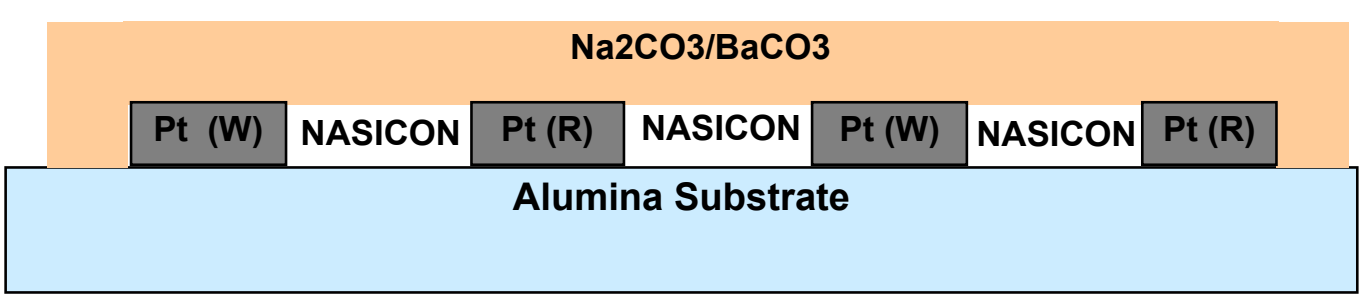

Side

Fig. 1 (a) Sensor with the interdigitated finger electrodes on the frontside (left), heater and temperature detector on the backside (right). (b) Partial side view of the $\mathrm{CO}_{2}$ sensor showing the NASICON and $\mathrm{Na}_{2} \mathrm{CO}_{3} / \mathrm{BaCO}_{3}$ electrolytes, the Pt interdigitated electrodes (both working $(\mathrm{W})$ and reference $(\mathrm{R})$ ), and the alumina substrate.

Commercially available alumina substrates (625 $\mu \mathrm{m}$ in thickness) [12] were patterned with photoresist and an interdigitated finger mask. Titanium $(50 \AA)$ and platinum $(4000 \AA)$ were sequentially deposited on the substrate by sputtering. After lift-off, the substrates with electrodes were pre-scribed for later separation (without actually dicing them) into individual devices before deposition of the electrolytes of NASICON and $\mathrm{Na}_{2} \mathrm{CO}_{3} / \mathrm{BaCO}_{3}$ [13]. Pre-scribing is necessary since both electrolytes on the completed sensor wafer could be degraded by the dicing process, which uses water as the cooling and lubricating agent. The pre-scribed substrates were then patterned again with photoresist and a second mask prior to NASICON deposition. This patterning covers the top of electrodes with photoresist. The solid electrolyte NASICON was then deposited by sputtering. A lift-off process was carried out using acetone to remove photoresist and unwanted NASICON on top of the interdigitated finger electrodes, resulting in the NASICON only remaining between the interdigitated fingers.

After depositing NASICON film, the device was heat-treated in an oven in air at $500^{\circ} \mathrm{C}$ for $20 \mathrm{~min}$ followed by $850^{\circ} \mathrm{C}$ for 2 hours with a ramp rate of $40^{\circ} \mathrm{C} / \mathrm{min}$ from room 
temperature to the desired temperatures. The auxiliary electrolytes $\mathrm{Na}_{2} \mathrm{CO}_{3} / \mathrm{BaCO}_{3}(1: 1.7$ molar ratio) [12] were sputter deposited on top of the interdigitated finger sensing area by using a shadow mask. The stoichiometries of both NASICON and $\mathrm{Na}_{2} \mathrm{CO}_{3} / \mathrm{BaCO}_{3}$ films were optimized by varying sputter parameters. The substrate with fabricated sensors was heated in an oven in air at $686^{\circ} \mathrm{C}$ for $10 \mathrm{~min}$ and then $710^{\circ} \mathrm{C}$ for 20 min with a ramp rate of $40^{\circ} \mathrm{C} / \mathrm{min}$. The pre-scribed substrate was then broken into individual sensors.

Fig. 2 is an SEM picture of the fabricated $\mathrm{CO}_{2}$ sensor. The interdigitated finger sensing area of the sensor is $1.0 \mathrm{~mm} \times 1.1 \mathrm{~mm}$. The thicknesses of NASICON and $\mathrm{Na}_{2} \mathrm{CO}_{3} / \mathrm{BaCO}_{3}$ are $3900 \AA$ and $3700 \AA$, respectively.

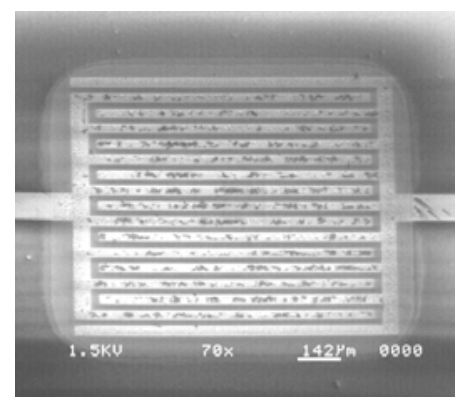

Fig. 2: SEM image of the $\mathrm{CO}_{2}$ sensor, NASICON was deposited in between interdigitated finger electrodes, and $\mathrm{Na}_{2} \mathrm{CO}_{3} / \mathrm{BaCO}_{3}$ were on top of the whole interdigitated fingers electrode area.

\section{Experimental Approach and Results}

The sensor was tested on a heater stage for temperature control using probe for electrical contact inside of a chamber. Gases were introduced into the chamber at a total flow rate of 4000 standard cubic centimeters per minute $(\mathrm{sccm})$. Different concentrations of carbon dioxide gas mixed in air were introduced at various temperatures up to $600^{\circ} \mathrm{C}$. The response of the sensor was measured by current output at a constant voltage. A series of tests were performed to optimize the operational parameters of the sensors. The testing parameters varied were the temperature and applied voltage.

The probes make contact with the sensor to measure the current across the interdigitated fingers. Since both sets of interdigitated sensor electrodes were in contact with the electrolytes in the same way, which electrode is used as the sensing electrode and which is used as the reference electrode does not make a difference in principle. However, the chemical reactions that make up the detection process change the electrolyte properties differently depending on whether it is a working or reference electrode. Thus, after testing has begun, there is a difference in properties between the two electrodes. The current direction was kept constant once a current flow direction was chosen.

\section{Operating Temperature Testing}

First, the optimum temperature for sensor operation was investigated. A series of $\mathrm{CO}_{2}$ gases with concentrations of $0.5 \%, 0.3 \%, 0.1 \%, 0.05 \%$, and $0.02 \%$ in air were used to test the sensor at $2 \mathrm{~V}$ at $600^{\circ} \mathrm{C}$ and $530^{\circ} \mathrm{C}$, respectively. Fig. 3 shows that the sensor response at $600^{\circ} \mathrm{C}$ was much higher than that at $530^{\circ} \mathrm{C}$. The baseline of the sensor in air 
tested at $530^{\circ} \mathrm{C}$ drifts with time, whereas baseline of the sensor in air tested at $600^{\circ} \mathrm{C}$ is much more stable. This difference in sensor stability is likely due to the fact that electrolytes equilibrate much faster at higher temperatures, minimizing the depletion of $\mathrm{Na}^{+}$ at the sensing (working) electrode. Therefore, an operation temperature of $600^{\circ} \mathrm{C}$ is preferable.

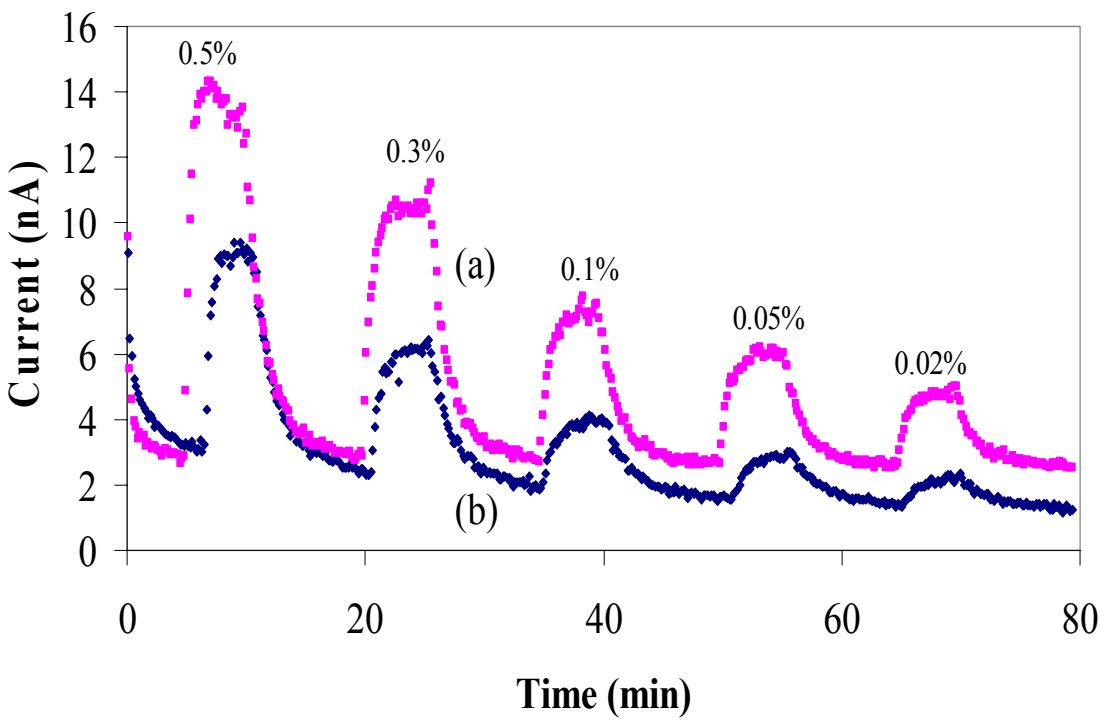

Fig. 3. Sensor response to $\mathrm{CO}_{2}$ gases with concentrations of $0.5 \%, 0.3 \%, 0.1 \%, 0.05 \%$, and $0.02 \%$ at $600^{\circ} \mathrm{C}(\mathrm{a})$ and $530^{\circ} \mathrm{C}(\mathrm{b})$ at a voltage of $2 \mathrm{~V}$.

\section{Applied Voltage Testing}

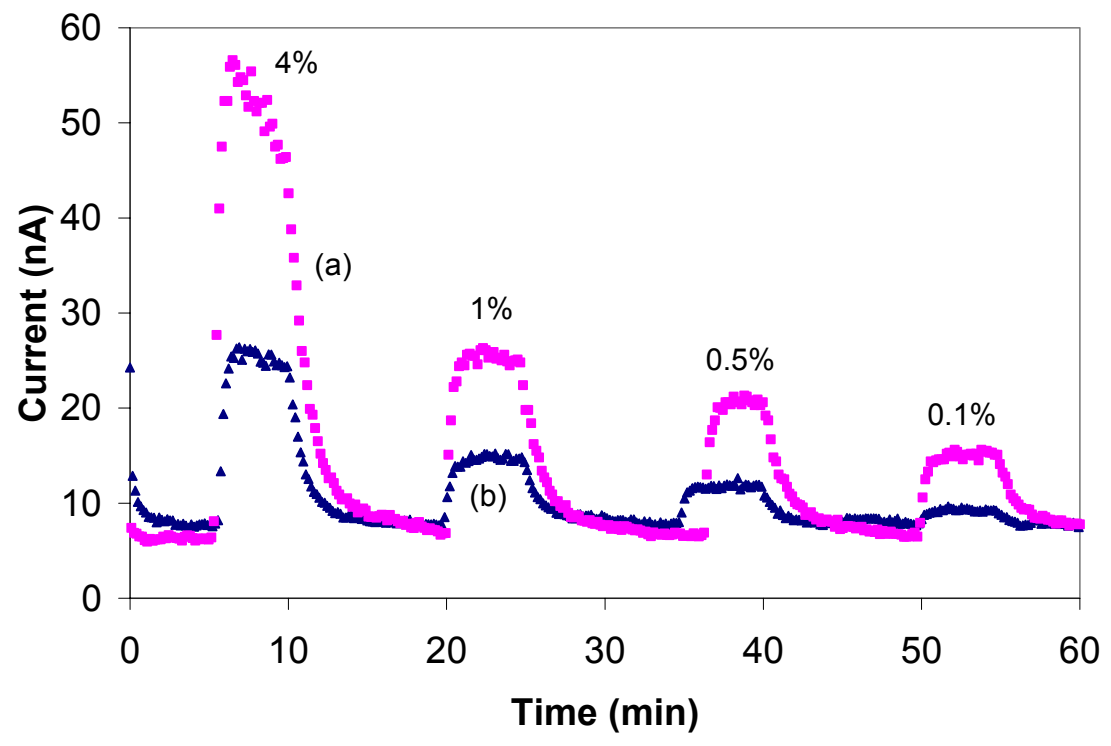

Fig. 4. Sensor response to $\mathrm{CO}_{2}$ gases with concentrations of $4 \%, 1 \%, 0.5 \%$, and $0.1 \%$ in air at (a) $2 \mathrm{~V}$ and (b) $1 \mathrm{~V}$ at a temperature of $600^{\circ} \mathrm{C}$.

The optimum testing voltage for the sensor was also evaluated. A series of $\mathrm{CO}_{2}$ gas with concentrations of $4 \%, 1 \%, 0.5 \%$, and $0.1 \%$ mixed in air was used at $600^{\circ} \mathrm{C}$ at $2 \mathrm{~V}$ and $1 \mathrm{~V}$, respectively. Fig. 4 shows that the sensor has a much higher response at an applied voltage of $2 \mathrm{~V}$ compared to that of $1 \mathrm{~V}$, although both applied voltages yield measurable 
responses through the concentration ranges measured. The baselines in air have similar values and are both stable. The testing results show that a temperature of $600^{\circ} \mathrm{C}$ was once again essential for a stable baseline. Given that both voltages gave sufficient responses to meet the sensitivity needs for the applications envisioned, a voltage of $1 \mathrm{~V}$ was chosen for further testing.

\section{Analyzing Sensor Response}

The sensor response versus $\mathrm{CO}_{2}$ gas concentrations was examined in more detail at $1 \mathrm{~V}$ and $600^{\circ} \mathrm{C}$. Fig. $5 \mathrm{a}$ shows the response at concentrations ranging from $0.02 \%$ to $2 \%$ in air. The sensor shows a relatively stable baseline after the first $\mathrm{CO}_{2}$ exposure with increasing current flow with increasing $\mathrm{CO}_{2}$ concentration. A plot of sensor current output versus $\ln \left[\mathrm{CO}_{2}\right.$ concentration $]$ shows a linear logarithmic relationship from $0.02 \%$ to $1 \% \mathrm{CO}_{2}(\mathrm{Fig}$. $5 b)$.
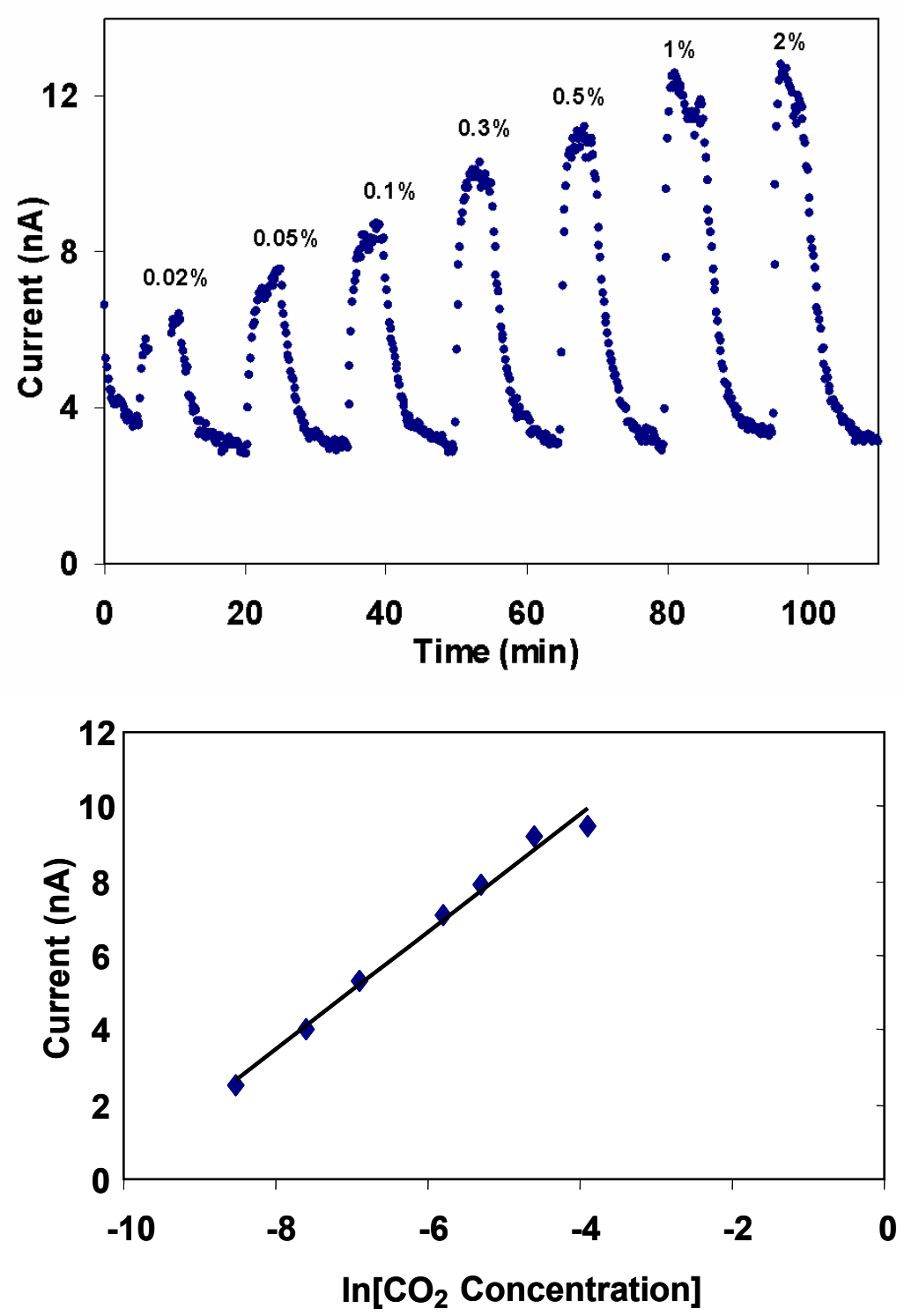

Fig. 5. (a) Sensor was tested in $\mathrm{CO}_{2}$ gases with concentrations of $0.02 \%, 0.05 \%, 0.1 \%$, $0.3 \%, 0.5 \%, 1 \%$ and $2 \%$ at $1 \mathrm{~V}$ and $600^{\circ} \mathrm{C}$. (b) Sensor current output versus $\ln \left[\mathrm{CO}_{2}\right.$ Concentration] 
The above results show that the miniature sensor has a wider detection range $(0.02 \%$ to $1 \%$ ) compared to the present existing solid electrolyte $\mathrm{CO}_{2}$ sensors which have much narrower linear response. e.g. $0.01 \%$ or $0.02 \%$ to $0.2 \%[5,13]$. The detection limit of $0.02 \%$ is lower than the typical $\mathrm{CO}_{2}$ concentration in air $(>0.03 \%)$ and $1 \%$ to $2 \% \mathrm{CO} 2$ is typically highest $\mathrm{CO}_{2}$ concentrations in most fires. Thus the sensor is suitable for both environmental monitoring and fire detection. The detection range could be further expanded if needed, due to the advantages of microfabrication in controlling the film thickness: Thinner electrolytes can yield a lower detection limit because most gas species could reach the sensing electrodes easily and thicker electrolytes can detect higher concentration of $\mathrm{CO}_{2}$ without being saturated due to the diffusion barrier function of the thick films. Different combinations of thicknesses of NASICON and $\mathrm{Na}_{2} \mathrm{CO}_{3} / \mathrm{BaCO}_{3}$ will be explored in the future to find proper thicknesses to achieve the application specified ranges.

\section{Sensing Mechanism}

The solid electrolyte sensor developed has a relatively stable baseline. This sensor was tested for three weeks and the baseline in air was consistently near or above $3 \mathrm{nA}$ at $600^{\circ} \mathrm{C}$. The sensor baseline could be recovered by heating the sensor overnight in air without applying any voltage to the sensor. Possible reasons for this stability might be found by examining the sensing mechanism.

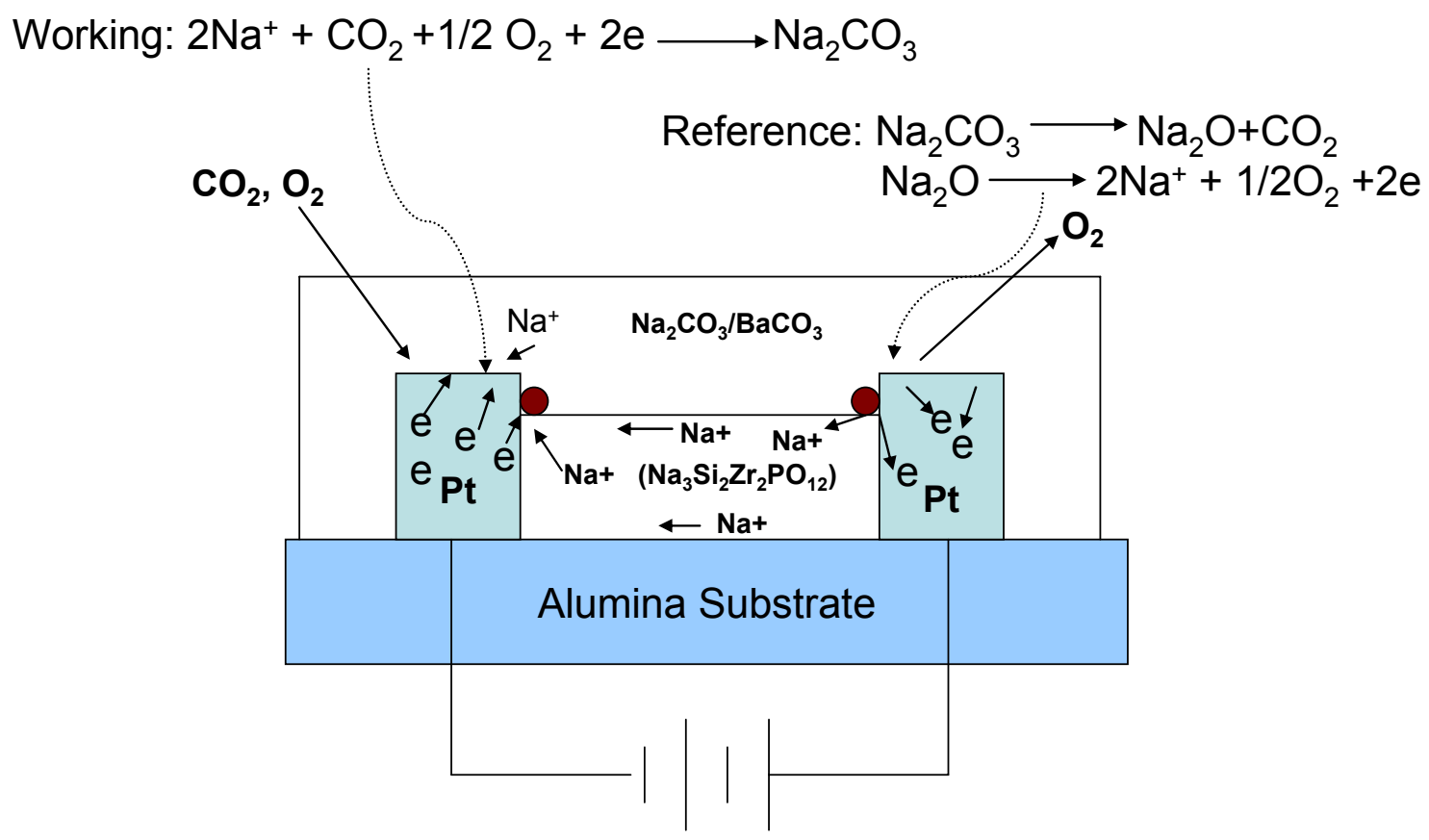

Fig. 6. Schematic sensing mechanism of the sensor with only two electrode fingers displayed. The areas highlighted by $\bullet$ in the figure are points of three-phase boundary. The overall design allows improved migration of ion species and improved sensor stability. 
The sensor schematic in Fig. 6 shows the sensing mechanism, with only two electrode fingers displayed for simplicity of discussion. As discussed in relation to Equation 1, the repeatable operation of the sensor significantly relies upon the current flow of $\mathrm{Na}^{+}$and regeneration of $\mathrm{Na}_{2} \mathrm{O}$ from $\mathrm{Na}_{2} \mathrm{CO}_{3}$. These processes rely on both the NASICON and $\mathrm{Na}_{2} \mathrm{CO}_{3} / \mathrm{BaCO}_{3}$ electrolytes. In previous work, the auxiliary electrolyte $\mathrm{Na}_{2} \mathrm{CO}_{3} / \mathrm{BaCO}_{3}$ (1:1.7) was deposited on only the working electrode [2]. In this present design, the auxiliary electrolyte was deposited homogeneously on the entire sensing area of the sensor, including both working (sensing) and reference electrodes. This allows improved flow of species within the electrolytes. For example, at the working electrode, the depleted $\mathrm{Na}^{+}$ concentration could be recovered by the transfer of $\mathrm{Na}^{+}$from NASICON through threephase boundary. In turn, the decreased concentration of $\mathrm{Na}^{+}$in NASICON could be supplemented from the $\mathrm{Na}_{2} \mathrm{CO}_{3} / \mathrm{BaCO}_{3}$ through the reference electrode three-phase boundary. The $\mathrm{Na}_{2} \mathrm{CO}_{3}$ deposited at the working electrode could be transferred to the reference electrode through the $\mathrm{Na}_{2} \mathrm{CO}_{3} / \mathrm{BaCO}_{3}$ if the temperatures are high enough to allow equilibration. These mechanisms allow the sensor to measure $\mathrm{CO}_{2}$ but recover back to its initial state easily. This process would be made more difficult if the $\mathrm{Na}_{2} \mathrm{CO}_{3} / \mathrm{BaCO}_{3}$ was not distributed across both the working and the reference electrodes.

Thus, the combination of the new pattern of the solid electrolytes with high operating temperatures allows the migration of species throughout the sensor structure. This allows the sensor to regenerate during operation, decreases the baseline drift, and improves overall sensor stability.

\section{Summary}

A miniaturized amperometric $\mathrm{CO}_{2}$ sensor was developed using microfabrication technology. This robust sensor has a structure of two distinctive sensing materials NASICON and $\mathrm{Na}_{2} \mathrm{CO}_{3} / \mathrm{BaCO}_{3}$ (1:1.7 in molar ratio) being deposited uniquely on interdigitated finger electrodes, forming much larger three-contact boundaries than other designs with similar dimensions. The sensor has advantages of being simple to fabricate, small in size, and easy to operate. The miniature $\mathrm{CO}_{2}$ sensor will be integrated with postage stamp-sized electronics and applied as "lick and stick". Future work includes integrating the heater with the sensor and further improving the sensor performance.

\section{Acknowledgements}

The authors gratefully acknowledge the contributions of those who made this paper and its contents possible: R. McKnight, Dr. L. Matus, G. Fralick, and T. Guo of NASA GRC; L. Chen of OAI; C. Chang of QSS/ NASA GRC; and S. Yu and Q. Wu of CWRU.

\section{References}

1. G. W. Hunter, C.C. Liu, and D. Makel, in MEMS Handbook Second Edition, Design and Fabrication, CRC Press LLC, ed. M. Gad-el-Hak, Boca Raton, Florida, Ch. 11, 2006. 
2. G. W. Hunter, L. G. Oberle, G. Baakalini, J. Perotti, and T. Hong, "Intelligent Sensor Systems for Integrated System Health Management in Exploration Applications," Proceedings of the First International Forum on Integrated System Health Engineering and Management in Aerospace, Nov. 2005, Napa, CA.

3. S. Yao, Y. Shimizu, N. Miura, and N Yamazoe, Chemistry Letters, 2033 (1990)

4. M. Holzinger, J. Maier, and W. Sitte, Solid State Ionics, 94, 217 (1997).

5. W. F. Chu, D. Fischer, H.Erdmann, M. Ilgenstein, H. Koppen and V. Leohard, Solid State Ionics, 53-56, 53 (1992).

6. Ji-Sun Lee, Jong-Heun Lee, and Seong-Hyeon Hong, Sens. Actuators, B96, 663 (2003).

7. Y. Yang, and C. C. Liu, Sens. Actuators, B62, 30 (2000).

8. E. Steudel, P. Birke and W. Weppner, Electrochim. Acta, 42, 3147-3153, (1997).

9. Y. Bang, K. Son, J. Huh, S. Choi and D. Lee, The 12th International Conference on Solid State Sensors, Actuators and Microsystems, 532, Boston, June 8-12, (2003).

10. B. J. Ward, C. C. Liu, and G. W. Hunter, Journal of Materials Science, 38, 4289 (2003).

11. N. Miura, M. Iio, G. Lu, and N. Yamazoe, Sens. Actuators, B35-36, 124 (1996).

12. Alumina substrate, $625 \mu \mathrm{m}$ in thickness (CoorsTec).

13. NASICON and $\mathrm{Na} 2 \mathrm{CO} 3 / \mathrm{BaCO} 3$ (1:1.7 in molar ratio) targets and pellets (Superconductive Component, Inc., Columbus).

13. F. Qiu, L. Sun, X. Li, M. Hirata, H. Suo, B. Xu Sens. Actuators, B45, 233 (1997) 